\title{
Permeability Evolution of Fractured Rock Subjected to Cyclic Axial Load Conditions
}

\author{
Zilong Zhou, ${ }^{1}$ Jing Zhang, ${ }^{1}$ Xin Cai $\mathbb{C}^{1},{ }^{1}$ Shanyong Wang, ${ }^{2}$ Xueming Du $\mathbb{D},{ }^{3}$ Haizhi Zang, ${ }^{1,2}$ \\ and Lu Chen ${ }^{4}$ \\ ${ }^{1}$ School of Resources and Safety Engineering, Central South University, Changsha 410083, China \\ ${ }^{2}$ Faculty of Engineering and Built Environment, ARC Centre of Excellence for Geotechnical Science and Engineering, The University \\ of Newcastle, Callaghan 2308, Australia \\ ${ }^{3}$ College of Water Conservancy and Environmental Engineering, Zhengzhou University, Zhengzhou 450001, China \\ ${ }^{4}$ School Civil Engineering, Changsha University Science and Technology, Changsha 410083, China
}

Correspondence should be addressed to Xin Cai; xincai@csu.edu.cn

Received 7 November 2019; Accepted 8 January 2020; Published 23 January 2020

Academic Editor: Paola Gattinoni

Copyright (c) 2020 Zilong Zhou et al. This is an open access article distributed under the Creative Commons Attribution License, which permits unrestricted use, distribution, and reproduction in any medium, provided the original work is properly cited.

\begin{abstract}
Permeability experiments on saw-cut fractured rock subjected to cyclic axial load conditions were conducted on the MTS815 rock mechanics testing system. The influence of the frequency and amplitude of cyclic axial forces on axial displacement and permeability evolution of fractured rock was experimentally investigated. Results show that the increasing frequency under the same amplitude of axial load leads to a reduction in axial displacement, but a drop followed by an increase in permeability, while the permeability values oscillated sharply under high amplitude of cyclic loads, which can be attributed to the production of gouge materials. Besides, the increase in axial displacement roughly contributed to the permeability reduction, and excessive amplitude of cyclic load posed limited boost to the permeability enhancement. By comparing with the quasistatic function, we found that it did not completely correspond to the trend of the permeability evolution subjected to cyclic axial forces, and sensitivity coefficients evolving with frequency and amplitude should be considered. A new function of the permeability evolution subjected to the amplitude and frequency of cyclic axial forces was derived and verified by the experimental data. This study suggests that small amplitude and high frequency of dynamic forces have the potential for enhancing the permeability of fracture and triggering the disaster of fractured rock.
\end{abstract}

\section{Introduction}

The permeability of fractured rock has received ample attention at different scales. At the crustal scale, the permeability of rock governs key geologic processes such as advective transport of heat and solutes and the generation of elevated fluid pressures [1], which has been recognized to relate to the plate motion, earthquakes, and large catastrophic slip [2-7]. In engineering practice, the permeability of fractured rock affects rock mass stability and its evolution triggers various engineering disasters $[8,9]$. For example, landslides usually happen after heavy rains, especially along with earthquakes [10-12].

A wide range of investigations on the permeability evolution of fractured rock mass subjected to normal stress has been conducted since the 1970s [13]. Iwai first tested the permeability of a fracture with a constant normal stress and found that the permeability of fracture decreases with the increase in normal stress [14]. Tsang and Witherspoon [15] and Raven and Gale [16] studied the effect of sample sizes on the normal stress-permeability properties of natural fractures and obtained empirical equations between the permeability of rock fractures and normal stress. Durham and Bonner [17] explored the impact of fracture migration on the permeability of fractured rock under normal stress and stated that, under the same normal stress, rocks with fracture migration possess a higher order of magnitude of permeability than those of a normal fracture. Lee and Cho [18] conducted laboratory hydraulic tests in linear flow on a rough rock fracture. The permeability of rough rock fractures 


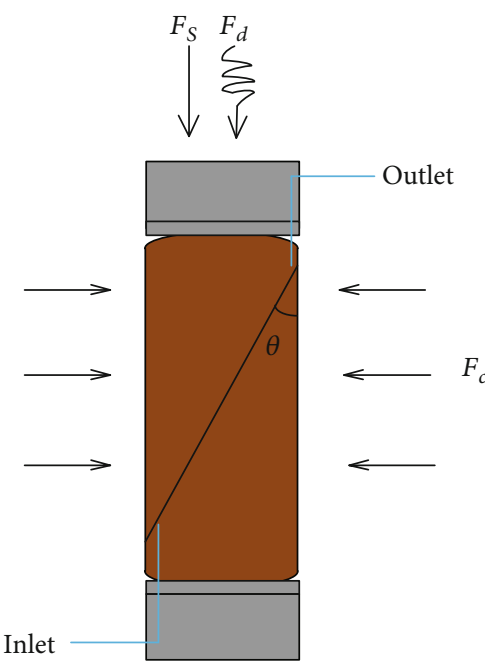

(a)

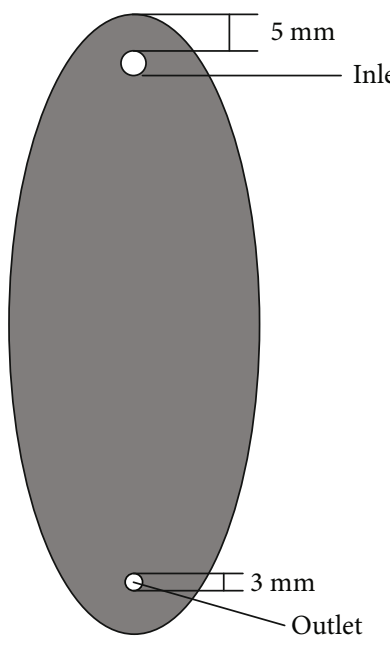

(b)

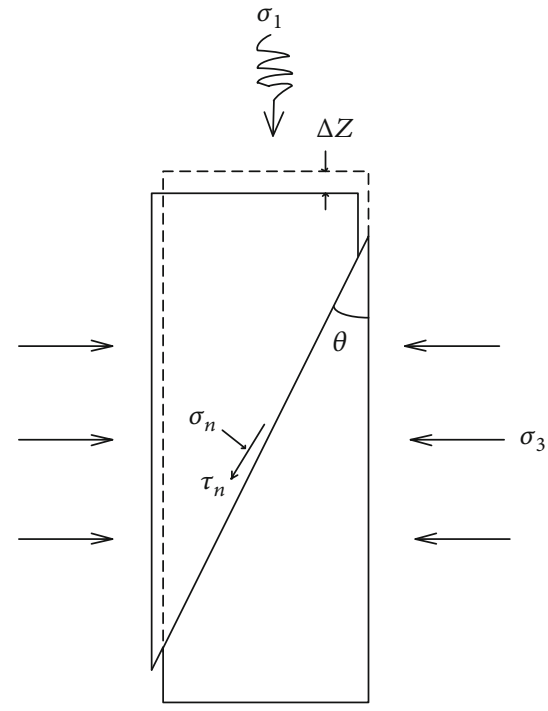

(c)

Figure 1: (a) Sketch of fractured rock sample; (b) a saw-cut fracture with boreholes for fluid flow; (c) sketch of fracture deformation during tests.

decays exponentially with respect to the normal stress. Researchers have paid much attention to the permeability of rock fractures considering the deformation behavior of rock fractures. Li et al. [19] conducted a series of shear-flow coupling experiments. Their results indicated that the permeability increases fast at the beginning of shear deformation, and then the growth continues at a lower rate until to the limit value. Olsson and Barton [20], Shi et al. [21], and Zhao et al. [22] adopted osmotic pressure to conduct shear-flow coupling test on rock fracture, and empirical formulas regarding the effect of contact area and surface roughness on fluid flow behavior were established. Zhang et al. [23] investigated the shear-induced permeability evolution in saw-cut sandstone fractures under triaxial stress condition. They suggested that the permeability decreases sharply with a minor increase in shear displacement at the stress growing stage. Wu et al. [24] examined the impacts of effective stress on the permeability evolution of slowly slipping fractures in Eagle Ford shale samples. Their results showed that the permeability of a fracture abates with the slip at high effective stress but goes up at low effective stress. Aforementioned studies of permeability evolution of fractured rock are limited in the quasistatic condition. Actually, rocks or rock masses are usually subject to cyclic disturbances, which probably come from earthquake, mining, and tunneling [25-34]. A large amount of studies suggested that cyclic loading can lead to severe fatigue damage or failure of rock even when the stress level is significantly lower than the static strength [35-47]. However, these studies only focus on the mechanical behavior of intact rock samples; whether cyclic loads affect the permeability of fractured rock is unknown. Hence, there is a need to understand the permeability characteristics of fractured rock under cyclic loads.

In this paper, the experiments of permeability evolution of saw-cut fractured rock subjected to cyclic axial loads were conducted on the MTS815 rock mechanics testing system. The permeability characteristics of fractured rock under different amplitudes and frequencies of dynamic axial load were investigated. In addition, a new formula on the permeability of fractured rock considering amplitudes and frequencies of cyclic axial load conditions was established.

\section{Methods}

2.1. Material Characterization and Sample Preparation. The rock material used in this study is a fine-grained sandstone collected from the northwest of Kunming, Yunnan province of China. A series of preliminary tests have been conducted on standard rock samples to determine the crucial mechanical parameters of the sandstone, such as Young's modulus $(34 \mathrm{GPa})$, Poisson's ratio (0.3), and uniaxial compressive strength $(86 \mathrm{MPa})$.

All samples were extracted from one single sandstone slab to minimize the variations in properties across the sample set [48]. Cylindrical samples $50 \mathrm{~mm}$ in diameter and $100 \mathrm{~mm}$ in length were first manufactured. Then, the samples were cut into two identical halves with an inclination of $30^{\circ}$ to the axial direction to simulate the fault plane, as shown in Figure 1(a). Subsequently, one borehole $3 \mathrm{~mm}$ in diameter was drilled parallel to the axial direction, at the corner of each half to facilitate fluid flow from core holders into the fracture (Figure 1(b)). After that, samples were saturated by soaking in water for more than 12 hours and then by water injection at a low pressure.

2.2. Experimental Setup and Procedure. All experiments were conducted on a servocontrolled rock mechanics testing system (MTS815) housed at the Advanced Research Center in Central South University. The system consists of five main units: a triaxial cell, a loading unit, a water supply unit, a 


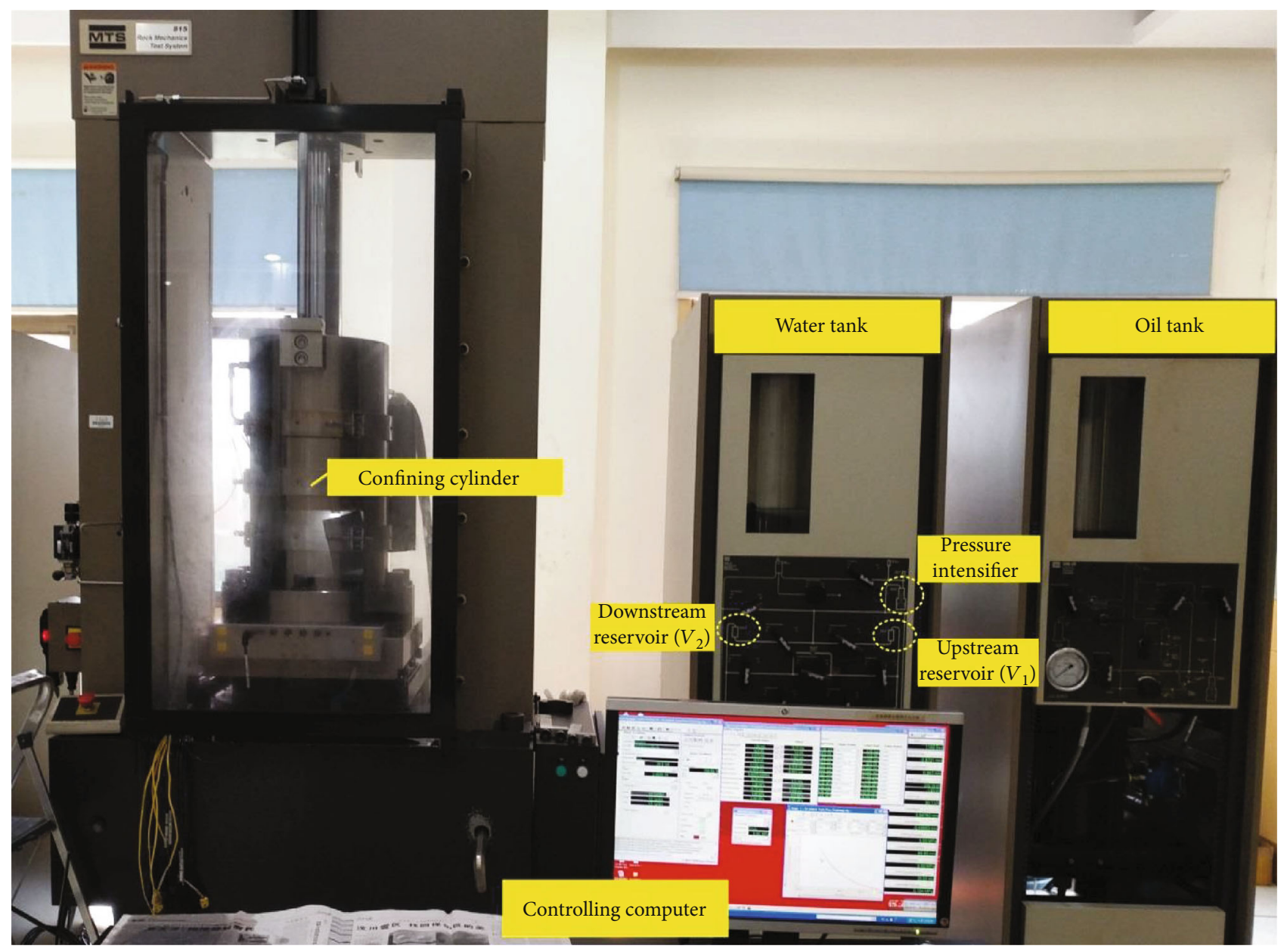

FIGURE 2: Schematic of transient permeability system.

deformation and pressure monitoring unit, and a dataacquisition unit. The maximum loading capacity of the system is up to $4600 \mathrm{kN}$. The maximum confining pressure and pore water pressure are $140 \mathrm{MPa}$. The axial deformation of the sample is measured by a pair of linear variable displacement transducers (LVDTs). The system is configured with a transient pulse apparatus for the permeability test of a cylinder rock specimen. The permeability was measured with a pressure pulse-decay technique testing method as shown in Figure 2. The experimental procedure includes the following steps:

(1) Each sample was wrapped in a Teflon tape to avoid the slippage in the opening fracture when exerting the confining stress and preaxial static load. Then, the sample was circumferentially sealed in a thermoshrinking plastic membrane to separate the sample from the confining fluid. After that, the rock sample was placed at the triaxial cell filled with hydraulic oil

(2) The confining stress $\left(\sigma_{3}\right)$ and static axial load $\left(F_{\mathrm{Sm}}\right)$ were successively increased to the designed levels at a constant loading rate of $0.1 \mathrm{MPa} / \mathrm{s}$. They were, respectively, set at $15 \mathrm{MPa}$ and $5 \mathrm{kN}$ in all tests and kept constant during the whole test
(3) Five minutes later, the sample and the loading system became stable. The successive axial sine wave was applied to the top of the sample by a rigid loading bar. The actual axial load is the superposition of the static preload and the cyclic load as

$$
F_{\mathrm{Sd}}=F_{\mathrm{Sm}}+F_{\mathrm{d}}(1+\sin (2 \pi f t)),
$$

where $F_{S d}$ is the superimposed axial force, $F_{S m}$ is the static axial load, $F_{\mathrm{d}}$ is the amplitude of dynamic axial force, $f$ is the frequency, and $t$ is the time. Preliminary compression tests on the fractured rock sample suggested that the critical axial load for the slippage of the sample under the confining pressure of $15 \mathrm{MPa}$ is $80.5 \mathrm{kN}$. Hence, the superimposed axial force should be limited below the critical load. In this study, the amplitude and the frequency of the cyclic load were independent variables as listed in Table 1. Four groups of tests were designed according to the amplitude of dynamic load, i.e., 10, 20, 30, and $40 \mathrm{kN}$. In each group, seven frequencies were set from $0.25 \mathrm{~Hz}$ to $1.75 \mathrm{~Hz}$. The loading paths with a frequency of $1 \mathrm{~Hz}$ were plotted in Figure 3 
TABLE 1: Test parameter for cyclic axial load conditions.

\begin{tabular}{|c|c|c|c|c|c|c|}
\hline Sample & Subset & $\sigma_{3}(\mathrm{MPa})$ & $F_{\mathrm{Sm}}(\mathrm{kN})$ & $F_{\mathrm{d}}(\mathrm{kN})$ & Cycles & $f(\mathrm{~Hz})$ \\
\hline & 1 & & & & & 0.25 \\
\hline & 2 & & & & & 0.5 \\
\hline & 3 & & & & & 0.75 \\
\hline \multirow[t]{7}{*}{ SC-1 } & 4 & 15 & 5 & 10 & 100 & 1 \\
\hline & 5 & & & & & 1.25 \\
\hline & 6 & & & & & 1.5 \\
\hline & 7 & & & & & 1.75 \\
\hline & 1 & & & & & 0.25 \\
\hline & 2 & & & & & 0.5 \\
\hline & 3 & & & & & 0.75 \\
\hline \multirow[t]{7}{*}{ SC-2 } & 4 & 15 & 5 & 20 & 100 & 1 \\
\hline & 5 & & & & & 1.25 \\
\hline & 6 & & & & & 1.5 \\
\hline & 7 & & & & & 1.75 \\
\hline & 1 & & & & & 0.25 \\
\hline & 2 & & & & & 0.5 \\
\hline & 3 & & & & & 0.75 \\
\hline \multirow[t]{7}{*}{ SC-3 } & 4 & 15 & 5 & 30 & 100 & 1 \\
\hline & 5 & & & & & 1.25 \\
\hline & 6 & & & & & 1.5 \\
\hline & 7 & & & & & 1.75 \\
\hline & 1 & & & & & 0.25 \\
\hline & 2 & & & & & 0.5 \\
\hline & 3 & & & & & 0.75 \\
\hline \multirow[t]{4}{*}{ SC-4 } & 4 & 15 & 5 & 40 & 100 & 1 \\
\hline & 5 & & & & & 1.25 \\
\hline & 6 & & & & & 1.5 \\
\hline & 7 & & & & & 1.75 \\
\hline
\end{tabular}

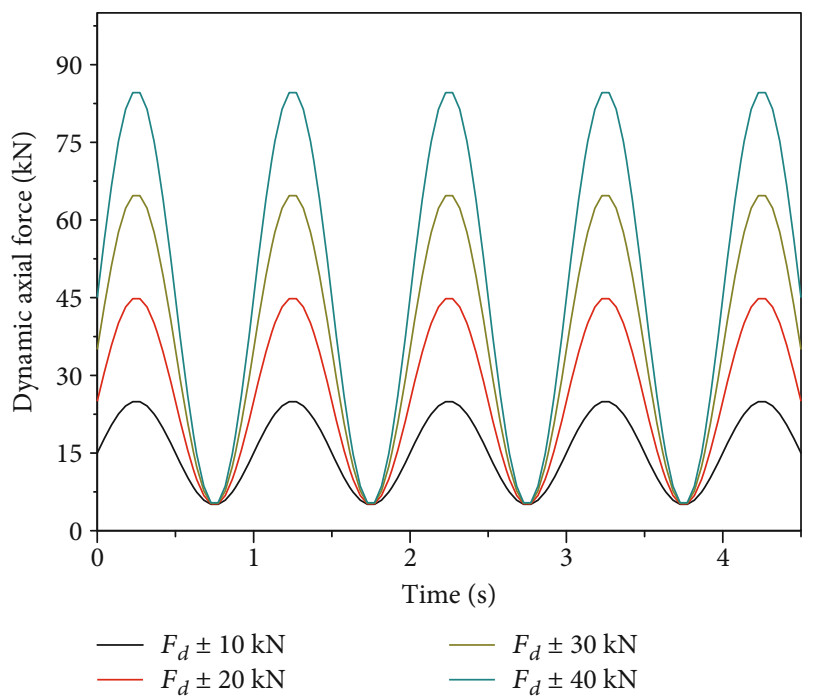

Figure 3: Schematic of loading paths with a frequency at $1 \mathrm{~Hz}$.
(4) After the sample was subjected to 100 cycles of dynamic disturbance, the cyclic loading stopped, and then the confining pressure and static axial load were still maintained at $15 \mathrm{MPa}$ and $5 \mathrm{kN}$. Then, an initial water pressure was applied to both the upstream and downstream reservoirs, at a loading rate of $0.2 \mathrm{MPa} / \mathrm{min}$. Next, the water pressure in the upstream reservoir suddenly increased to form a differential pressure (i.e., an initial pulse pressure) which makes the water flow from the top to the bottom through the fracture, as shown in Figure 2. The time pulse pressure $(\Delta P)$ decreased over time until equilibrium was attained. It was automatically monitored and recorded by two pressure gages in the water tank. Accordingly, the permeability of the fractured sample can be obtained (see Section 2.3.2)

\subsection{Data Reduction}

2.3.1. Axial Stress on Rock Sample and Normal Stress on Fracture Plane. As shown in Figure 1(c), the axial stress of the sample can be expressed as

$$
\sigma_{1}=\frac{F_{\mathrm{Sm}}+F_{\mathrm{d}}(1+\sin (2 \pi f t))}{A_{1}},
$$

where $A_{1}$ is the cross-sectional area of the sandstone sample.

The effective normal stress of the fracture plane is

$$
\begin{aligned}
\sigma_{\mathrm{n}} & =\left(\sigma_{3}-P_{\mathrm{m}}\right)+\left(\sigma_{1}-\sigma_{3}\right) \sin ^{2} \theta \\
& =\left(\sigma_{3}-P_{\mathrm{m}}\right)+\left(\frac{F_{\mathrm{Sm}}+F_{\mathrm{d}}(1+\sin (2 \pi f t))}{A_{1}}-\sigma_{3}\right) \sin ^{2} \theta,
\end{aligned}
$$

where $\sigma_{\mathrm{n}}$ is the effective normal stress and shear stress on the facture plane; $\theta$ is the fracture inclination angle with respect to the vertical axis of the sample $\left(30^{\circ}\right.$ in this experiment); $\sigma_{1}$ and $\sigma_{3}$ are the effective normal stress and confining pressure of the sandstone sample, respectively; and $P_{\mathrm{m}}$ is the average value of the upstream pressure and downstream pressure.

2.3.2. Permeability. Rock permeability can be measured using a steady state method, in which the flow rate of a fluid through a sample is measured for a known hydraulic pressure gradient. When permeability is low, however, a long time may be required to establish a steady state. Therefore, the pressure pulse-decay technique which was pioneered by Brace et al. [49] has been widely used to measure the permeability of relatively low-permeability saw-cut fractured rocks [50]. This method is based on the analysis of the decay of a small-step change of the pressure imposed at one end of a specimen. In this study, the differential pressure along the fault plane after achieving a pressure step is measured, then the permeability is calculated as [24]

$$
k=\frac{c L \mu}{A_{2} P_{\mathrm{m}}\left(1 / V_{1}+1 / V_{2}\right)},
$$




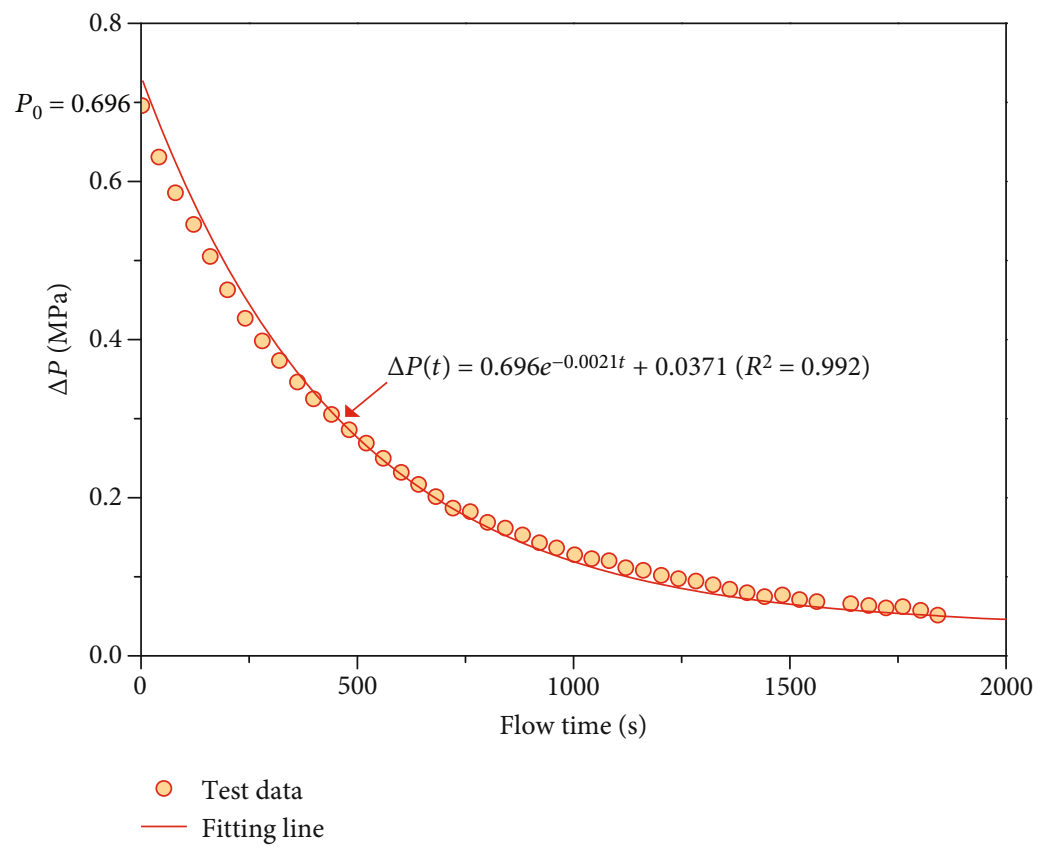

FIgURE 4: A representative differential pressure versus flow time curve.

where $P_{\mathrm{m}}$ is the average value of $P_{V_{1}}$ and $P_{V_{2}} ; P_{V_{1}}$ and $P_{V_{2}}$ are the upstream pressure and downstream pressure, respectively; $\mu$ is the water viscosity $\left(1.01 \times 10^{-3} \mathrm{~Pa} \cdot \mathrm{s}\right)$; $L$ is the distance between the two drilled boreholes along the fault plane; $A_{2}$ is the cross-sectional area of the fracture; $V_{1}$ and $V_{2}$ are the upstream and downstream reservoir volumes, respectively $\left(V_{1}=V_{2}=3.32 \times 10^{-7} \mathrm{~m}^{3}\right.$ for the MTS experimental setup as shown in Figure 2); and $c$ is the rate of the variation rate of the time pulse pressure with time, which can be determined according to the evolution of the time pulse pressure $(\Delta P)$. Brace et al. [49] and Jang et al. [51] suggested that the time pulse pressure exponentially attenuates with time as

$$
\Delta P(t)=P_{0}\left(e^{-c t}\right)+c_{0}
$$

where $P_{0}$ is the initial pulse pressure at time $t=0$ and $c_{0}$ is a fitting constant. Figure 4 presents the variation of the time pulse pressure versus time. It can be seen that the decay model of the time pulse pressure (Equation (5)) matches the trend of test data well. Clearly, the coefficient $c$ is 0.0021 .

\section{Results and Discussion}

3.1. Effects of Loading Frequency on the Permeability of Fractured Rock. Figure 5 shows that the permeability and the axial displacement vary with frequencies. Figure 5(a) presents that the permeability value at $0.25 \mathrm{~Hz}$ is greater than the one at $0.5 \mathrm{~Hz}$, and the other three groups of different amplitudes of axial dynamic forces (shown in Figures 5(b)-5(d)) show the same trend. Under a given amplitude of cyclic load, the permeability first falls sharply to the minimum value and then rises gradually with the increase in frequency. The frequency at which the lowest permeability appears in each group varies, and it seems that the high amplitude of dynamic forces $(30 \mathrm{kN}$ and $40 \mathrm{kN})$ intensifies the reduction of permeability. By contrast, the largest increment of permeability in each group appears when the highest frequency is reached, except for the one under the axial dynamic force of $\pm 40 \mathrm{kN}$, at the frequency of $0.25 \mathrm{~Hz}$. It can be interpreted as that the additional fluid flow pathways being created by the damage of fracture contacts under high amplitude give rise to the permeability enhancement [24].

It is clear that low frequencies of axial dynamic force contribute to the deformation of rock fractures. The axial displacement shows a steady decline with the increase in frequency in different groups. While under the axial dynamic force of $30 \mathrm{kN}$ (shown in Figure 6(c)), it surges in the vicinity of $0.75 \mathrm{~Hz}$ followed by a fluctuation. The other three groups see the largest axial displacement at the frequency of $0.25 \mathrm{~Hz}$. This irregular variation may be attributed to the production of gouge materials. Figure 6 shows that during the fracture slippage, fracture surfaces are ground down, and the coarse grains on surfaces are crushed into fine powder and produce gouge materials [23]. The gouge material transport tends to occur during increasing frequencies when the rock material is crushed under a more intensive multiple dynamic impact and becomes easy to transport. This observed gouge material production could potentially cause the hysteretic behavior by subsequently clogging flow paths, thus adding or lowering the fracture permeability and bringing about the irregular permeability values [52].

From Figure 7, the permeability of the fractured rock also varies with the axial deformation. The highest permeability is recorded at the smallest axial displacement of $1.3 \times 10^{-2} \mathrm{~mm}$, which roughly accords with the conception that the permeability generally decreases with increasing axial displacement. However, this trend fluctuates abnormally during which the permeability rises rapidly from the deformation 


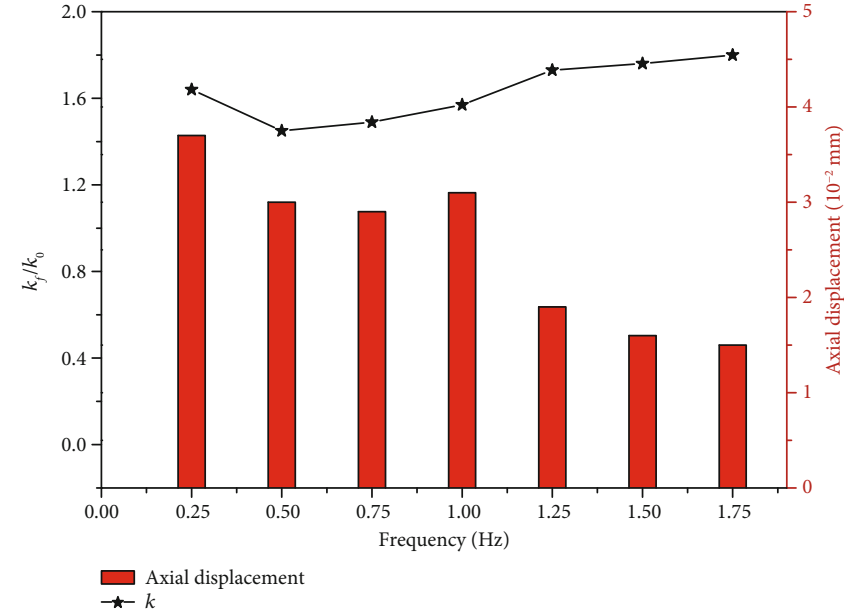

(a)

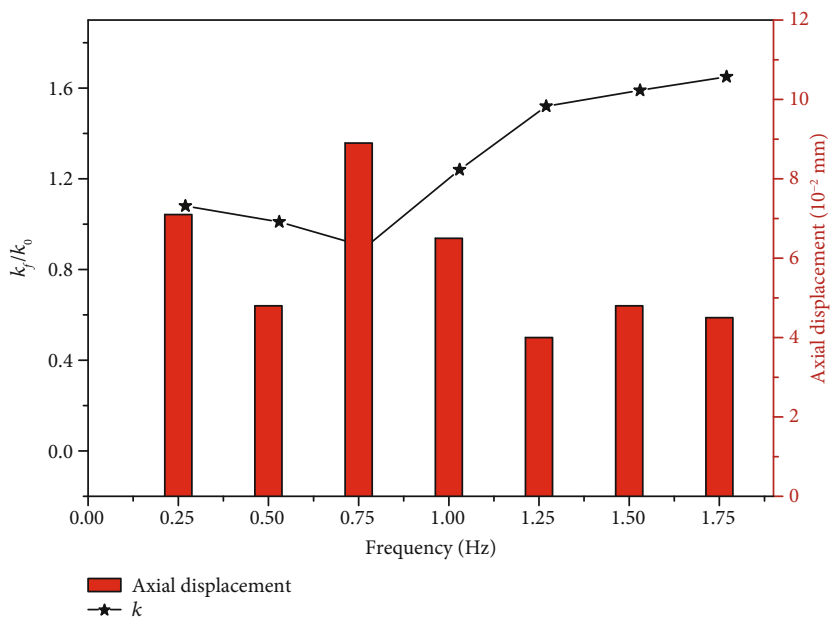

(c)

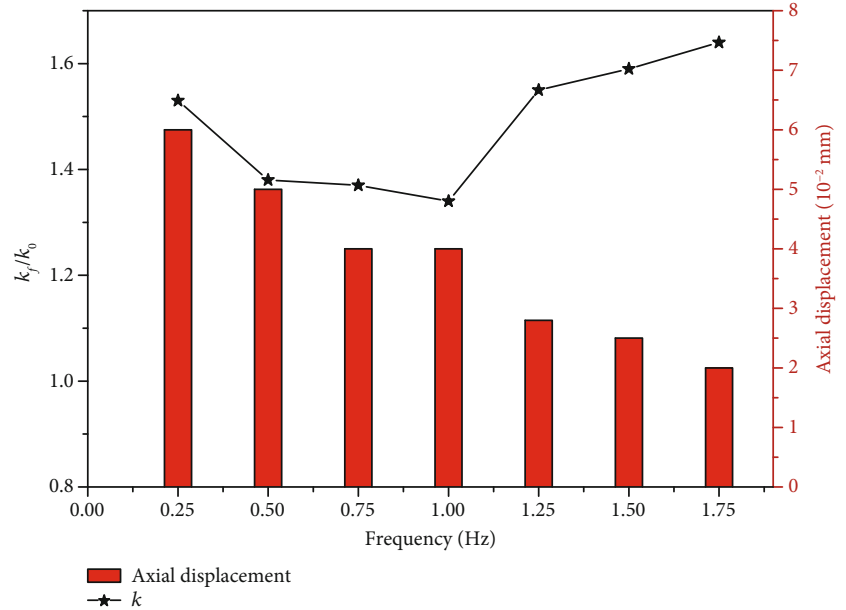

(b)

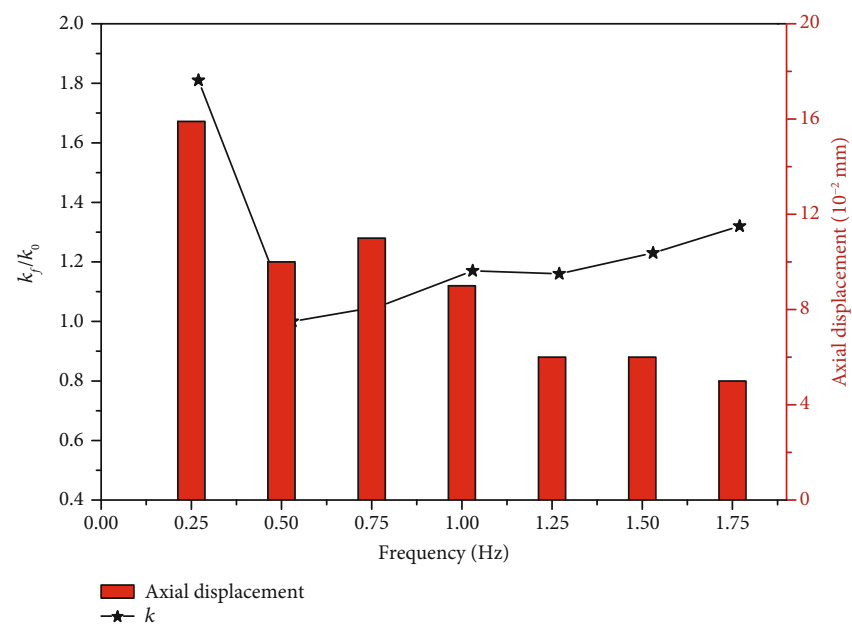

(d)

Figure 5: Permeability evolution of fracture and variation of axial displacement under different frequencies in amplitudes of dynamic axial force of $10 \mathrm{kN}, 20 \mathrm{kN}, 30 \mathrm{kN}$, and $40 \mathrm{kN}$ : (a) $10 \mathrm{kN}$ in amplitude of dynamic axial force; (b) $20 \mathrm{kN}$ in amplitude of dynamic axial force; (c) $30 \mathrm{kN}$ in amplitude of dynamic axial force; (d) $40 \mathrm{kN}$ in amplitude of dynamic axial force. (In these figures, the red lines represent axial displacement and the black lines show permeability versus frequency. Permeability after periodic slip $\left(k_{f}\right)$ normalized by the permeability prior to any cyclic axial forces $\left.\left(k_{0}\right)\right)$.

of $3 \times 10^{-2} \mathrm{~mm}$ to $4 \times 10^{-2} \mathrm{~mm}$ in the amplitude of $10 \mathrm{kN}$, and the permeability fluctuates greatly from the deformation of $4 \times 10^{-2} \mathrm{~mm}$ to $5 \times 10^{-2} \mathrm{~mm}$ in the amplitude of $30 \mathrm{kN}$. A rational explanation is that the accumulation of gouge materials in the sliding of the fracture causes a large change in permeability.

Generally, the change in axial displacement counteracts that in permeability. The reason may be that the reduction in the axial deformation with decreasing axial displacement broadens the fracture apertures, creating more flowing pathways. The other reason is that the permeability of fractured rock falls with varying slip displacement that rubs down the bumped edge of the fracture surface [53]. It produces the gouge production that can strongly counteract the permeability growth caused by slip displacement [52]. Similar observations were obtained by Fang et al. [7], who found that against such a background, the fractured rock permeability steadily decreases with increasing slip distance. An upward step of sliding velocity could provoke a transient but small increment of permeability that is quickly quenched by the downward permeability trend. However, the trend that the slip displacement changes with frequency is opposite to the experimental result in [54]. This is because axial stresses varying with time instead of axial strain varying with time as applied by Liu and Manga [54] are adopted in the current study, whereas the permeability changes with displacements match well with the results reported by them. Therefore, it is worth stating that the permeability drops with the growth of axial displacement in a saw-cut fracture. Similarly, our results show that overall, the axial displacement decreases with the increase in frequencies, while the permeability rises after each group of frequencies, and the increment of permeability is progressively smaller with each additional application of frequencies. 


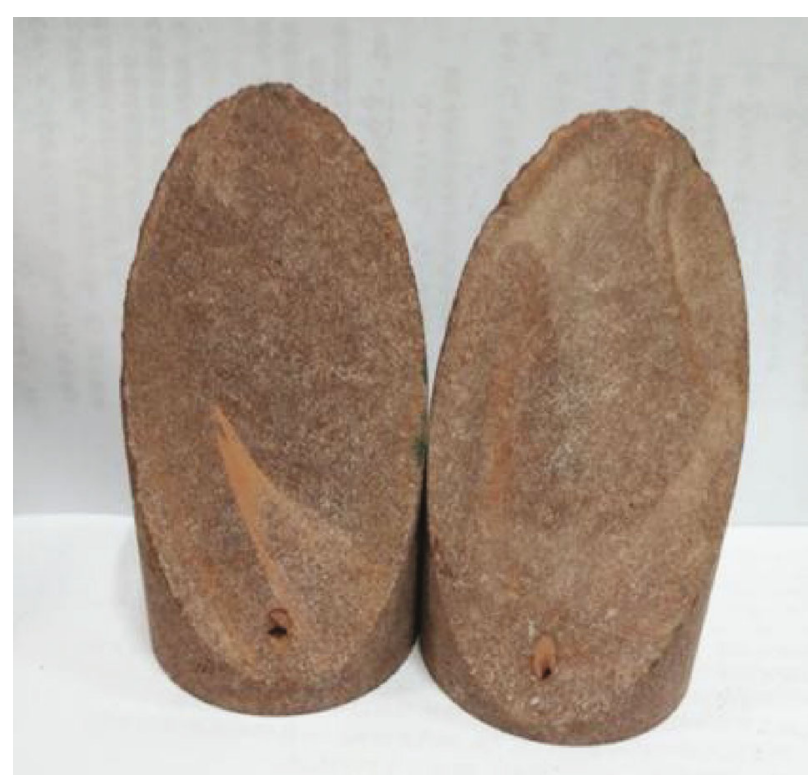

(a) Before test

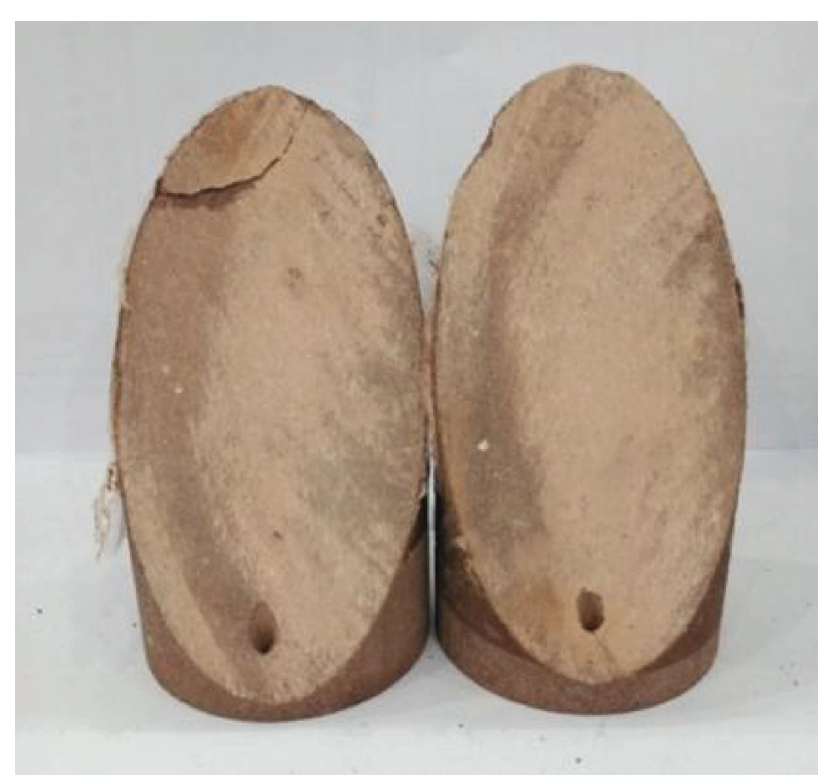

(b) After test

FIgURE 6: Comparison of untested fracture surfaces and tested fracture surfaces of SC-5.

3.2. Effects of Cyclic Amplitude on the Permeability of Fractured Rock. The permeability of fractured rock is strongly correlative with the amplitude of dynamic axial forces. As shown in Figure 8, overall, most of the groups show an apparent reduction in the permeability with the rising amplitude of cyclic forces. An exception is the state at the frequency of $0.25 \mathrm{~Hz}$, in which the permeability of fracture decreases sharply by $30 \%$ with the growth of dynamic axial forces from $\pm 10 \mathrm{kN}$ to $30 \mathrm{kN}$ but followed by an almost double surge. Because there is a strong sliding behavior at the frequency of $0.25 \mathrm{~Hz}$ under dynamic axial forces of $40 \mathrm{kN}$, the permeability is lifted greatly. The similar phenomenon occurs at the frequency of $0.75 \mathrm{~Hz}$. It should be noted that the drop of permeability does not completely correspond to the descending series of frequency, in particular the frequency of $0.25 \mathrm{~Hz}$ in which the enhancement of permeability is even higher than $1 \mathrm{~Hz}$. This is probably due to the existence of gravel particles in rough fractures before test, and then the first periodic slip greatly enhances the permeability of fracture at $0.25 \mathrm{~Hz}$. However, excessive amplitude poses a limited boost to the permeability, unless raising the frequencies up to $1.25 \mathrm{~Hz}$. The permeability under low frequencies $(0.25 \mathrm{~Hz}, 0.5 \mathrm{~Hz}$, and $0.75 \mathrm{~Hz})$ is increased less than $10 \%$ when the amplitude is over $\pm 30 \mathrm{kN}$. The fractured rock probably is easily compressed under low frequencies with the increase of amplitude, which leads to a lower increase in permeability.

The variation of axial displacement with different amplitudes of dynamic loads is depicted in Figure 9. Larger amplitudes of axial force have larger reduction in axial displacement. Given that the compressive deformation of fractured rock increases as the amplitude of dynamic axial forces increases, meanwhile, the decrease in the fracture width of fractured rock weakens the permeability. These results match those observed in earlier studies that perme- ability decreases sharply with increasing slip displacement at the stage of stress growth [18]. This suggests that small amplitudes of dynamic forces can reduce slipping deformation and enhance the permeability. That could explain the fact that small dynamic strains are able to seriously destabilize loaded faults by increasing the permeability in earthquake-triggered stress waves [55], and the permeability in a fractured rock system is increased significantly by the small stresses in seismic waves from regional earthquakes [56]. The permeability changes are similar to those found by Liu and Manga, and it is deemed that the permeability decreases with each additional application of transient stress [54].

\subsection{Prediction Model for the Permeability of Fractured Rock} Subjected to Cyclic Loads. The stress-dependent evolution of permeability is one of the dominant attributes of fractured rock $[23,57]$. The equation of permeability with normal stress has been widely used in some literature. However, the equation of permeability with dynamic stress is rarely reported. In this paper, the equation of permeability under cyclic axial load is established by considering the coefficients of frequency and amplitude, and the accuracy of the equation is verified by fitting the experimental data.

Previous studies show that the change in permeability depends on the effective stress, which could be described as an exponential function [16]:

$$
k=k_{0} e^{\left(-\beta \sigma^{\alpha}\right)}
$$

where $\sigma$ is the effective stress, $k_{0}$ is the intrinsic permeability, and $\alpha$ and $\beta$ are the stress sensitivity coefficients.

However, the abovementioned model is limited to the static condition; the amplitude and frequency of dynamic disturbance are not considered. Here, we substitute Equation 


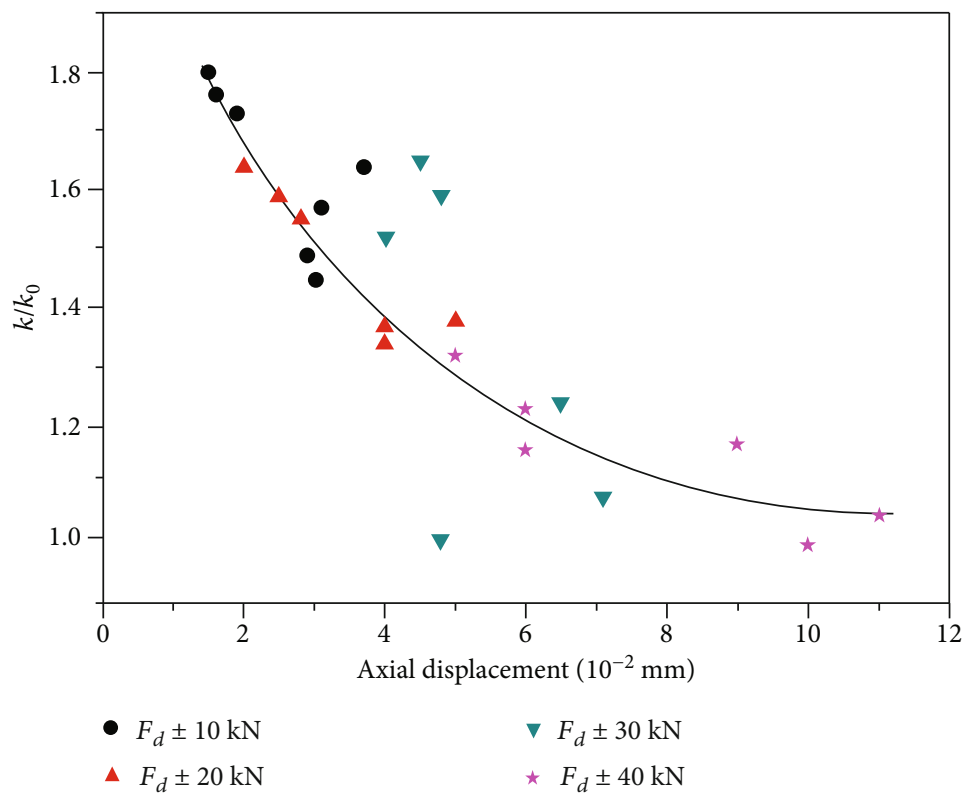

Figure 7: Permeability evolution of fracture with axial displacement in different amplitudes of dynamic axial force.

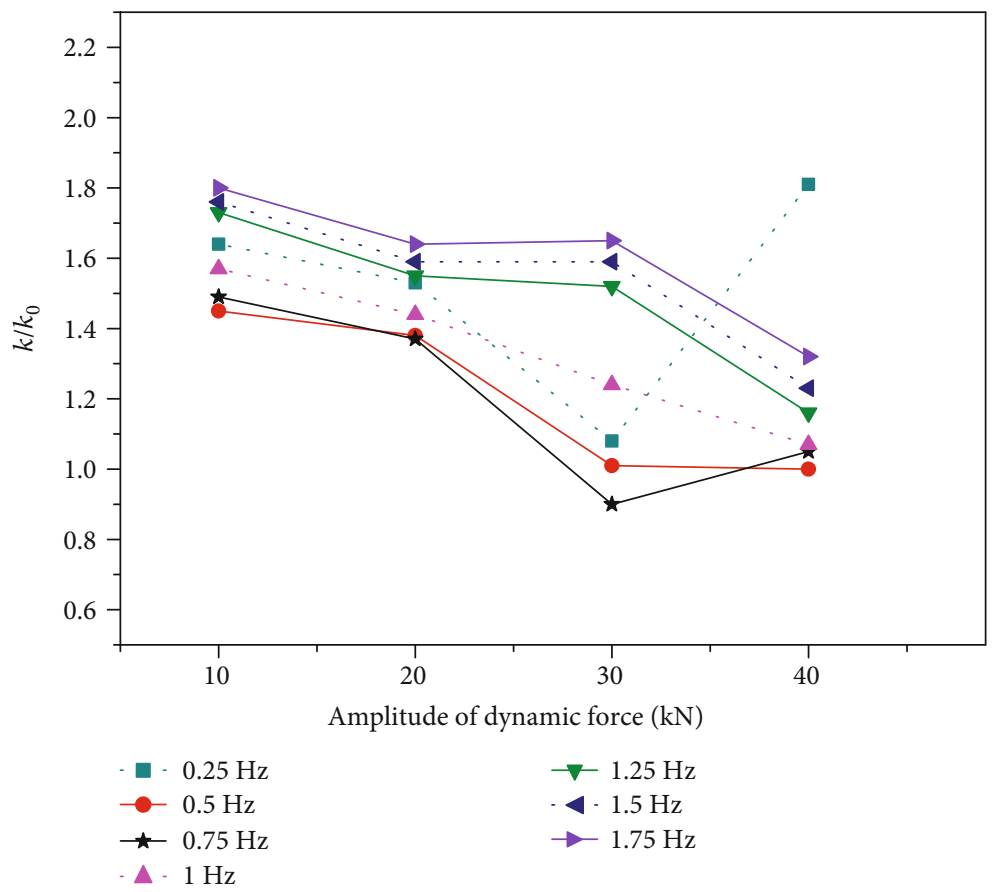

FIgURE 8: Permeability evolution of fracture in different amplitudes of dynamic normal force under frequencies.

(3) into Equation (6) to characterize the permeability of fractured rock under cyclic loads as

$$
k_{\mathrm{f}}=k_{0} e^{\left(-\beta \sigma_{\mathrm{n}}{ }^{\alpha}\right)}=k_{0} e^{\left(-\beta\left(\left(\sigma_{3}-P_{\mathrm{m}}\right)+\left(\frac{F_{\mathrm{Sm}}+F_{\mathrm{d}}(1+\sin (2 \pi f t))}{A_{1}}-\sigma_{3}\right) \sin ^{2} \theta\right)^{\alpha}\right)} .
$$

For comparison, the fitting curves of permeability evolution with the frequency and amplitude of cyclic axial loads using the traditional model Equation (6) and improved model Equation (7) are shown in Figures 10 and 11. Appar- ently, the correlation coefficients between the permeability evolution with the frequency of dynamic axial forces by traditional model and by improved model have little difference (Figure 10). By contrast, the correlation coefficients of the permeability evolution with amplitude of dynamic axial forces by the traditional model are greater than that by the improved model (Figure 10). From Figure 11, it can be seen that the fitting curves by the traditional model show large deviations with the tested data. The determination coefficients are very low. These indicate that the traditional model is not suitable for describing the relation between the 


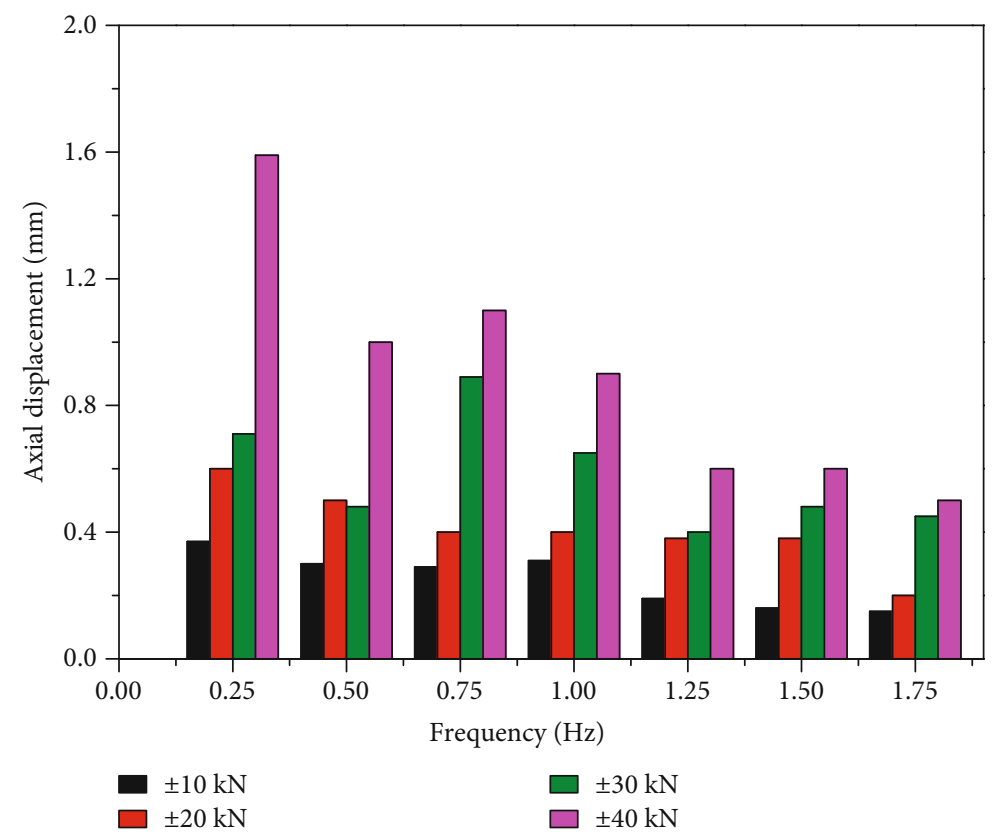

FIgURE 9: Variation of axial displacement with amplitude.

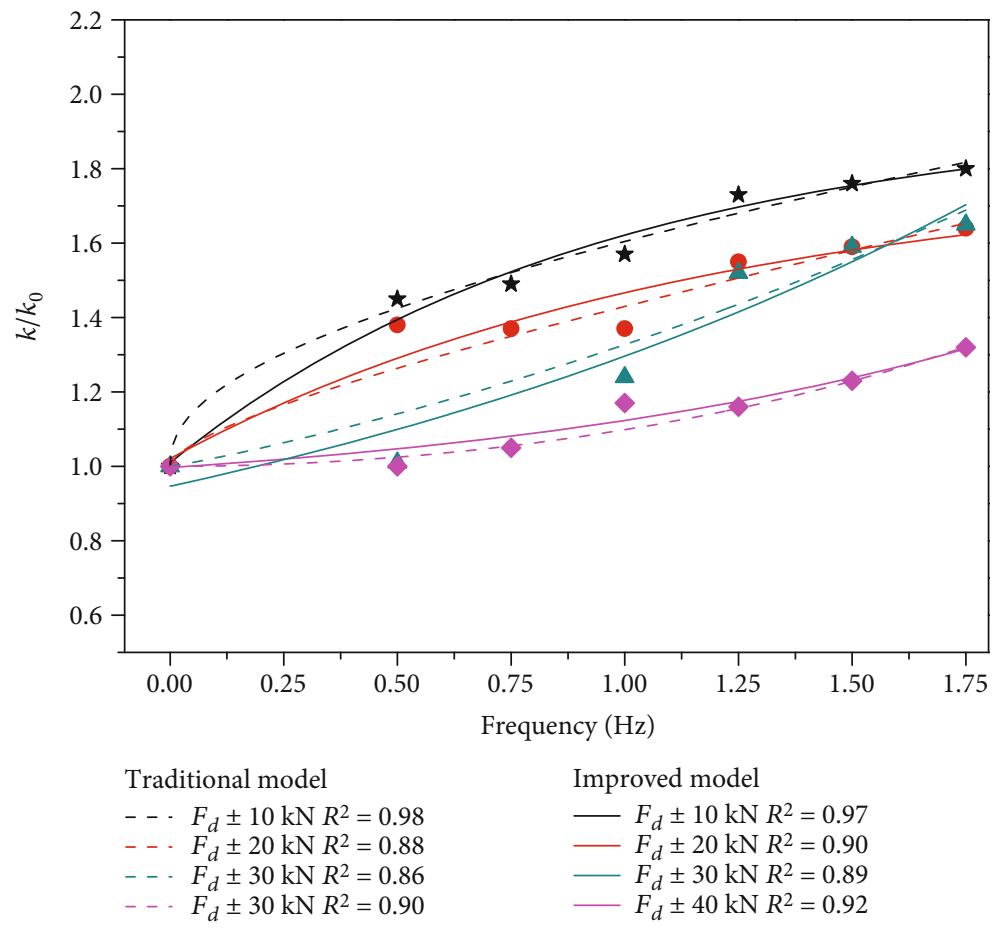

FIGURE 10: Fitting curves of permeability evolution with frequency by traditional model Equation (6) and improved model Equation (7).

permeability and the amplitude of the cyclic load. The improved model Equation (7), however, can obtain the average correlation coefficients greater than 0.87 . Therefore, the change in permeability with cyclic axial load fits in the improved model Equation (7) rather than the traditional model Equation (6). Figures 10 and 11 show that the permeability increases with frequency and declines with increasing amplitude. This indicates that smaller amplitude and higher frequency of dynamic forces have more potential to enhance the permeability of fracture accordingly and increase the risk of disaster in rock engineering.

\section{Conclusions}

The permeability evolution of saw-cut rock fractures was investigated before and after the periodic slip caused by cyclic axial loads, so as to simulate the permeability evolution of preexisting fractures under dynamic loads in fractured rock 


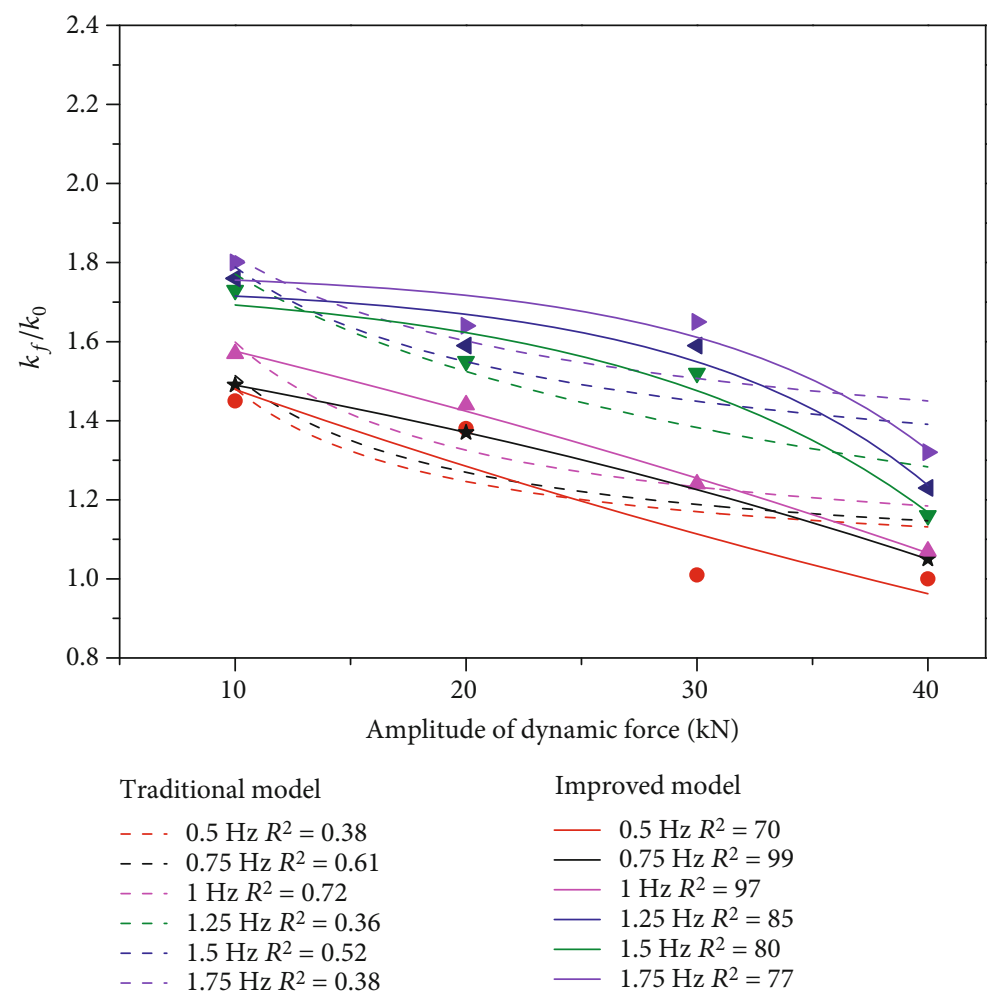

FIGURE 11: Fitting curves of permeability evolution with amplitude by traditional model Equation (6) and improved model Equation (7).

engineering. Based on a series of experiments under different dynamic frequencies, different amplitudes of cyclic axial forces were conducted, by which the slip behavior of rock fractures was analyzed. The main findings of this paper can be summarized as follows:

(1) Increasing the frequency of cyclic loads under the same amplitude leads to an increase in axial displacement. The initial application of the cyclic load greatly boosted the slip behavior, followed by a gradual decrease in axial displacement after applying each group of frequencies. While this trend may fluctuate due to the production of gouge materials during fracture slippage, in which the crushed rock materials were transported and thus creating more flow channels. This behavior also explains the hysteretic permeability drop as successive cyclic loads were conducted. However, the permeability of rock fracture first fell down and then rose to the highest value under the same amplitude (except for the status in amplitude of $\pm 40 \mathrm{kN}$ ). It can be attributed to the transport of rock debris that introduced the irregular clogging during experiments afterwards

(2) The permeability of fractured rock roughly decreased with the growth of axial displacement. Besides, the fluctuated permeability proved the accumulation of gouge materials in fracture sliding

(3) The quasistatic function did not completely correspond to the permeability evolution subjected to cyclic axial forces, and sensitivity coefficients evolv- ing with frequency and amplitude should be considered. The equation of permeability under cyclic axial loads was established by considering the coefficients of frequency and amplitude, and the accuracy of the equation was verified by fitting the experimental data. Our results reveal that the small amplitude and high frequency of dynamic forces have the potential to enhance the permeability of fracture and increase the risk of disaster in rock engineering

\section{Data Availability}

The test data in this paper is available upon request.

\section{Conflicts of Interest}

The authors declare that there is no conflict of interest regarding the publication of this paper.

\section{Acknowledgments}

This work was supported by the National Basic Research Program of China (973 Program) (2015CB060200), the National Natural Science Foundation of China (41772313), the Hunan Science and Technology Planning Project (No. 2019RS3001), and the Graduated Students' Research and Innovation Fund Project of Hunan Province (CX20190135 and 2019zzts079). 


\section{References}

[1] M. Manga, I. Beresnev, E. E. Brodsky et al., "Changes in permeability caused by transient stresses: field observations, experiments, and mechanisms," Reviews of Geophysics, vol. 50, no. 2, 2012.

[2] P. Segall, "Earthquakes triggered by fluid extraction," Geology, vol. 17, no. 10, pp. 942-946, 1989.

[3] A. R. Lowry, "Resonant slow fault slip in subduction zones forced by climatic load stress," Nature, vol. 442, no. 7104, pp. 802-805, 2006.

[4] Y. Guglielmi, F. Cappa, J. P. Avouac, P. Henry, and D. Elsworth, "Seismicity triggered by fluid injection-induced aseismic slip," Science, vol. 348, no. 6240, pp. 1224-1226, 2015.

[5] A. McGarr, B. Bekins, N. Burkardt et al., "Coping with earthquakes induced by fluid injection," Science, vol. 347, no. 6224 , pp. 830-831, 2015.

[6] J. L. Rubinstein and A. B. Mahani, "Myths and facts on wastewater injection, hydraulic fracturing, enhanced oil recovery, and induced seismicity," Seismological Research Letters, vol. 86, no. 4, pp. 1060-1067, 2015.

[7] Y. Fang, D. Elsworth, C. Wang, T. Ishibashi, and J. P. Fitts, "Frictional stability-permeability relationships for fractures in shales," Journal of Geophysical Research, vol. 122, no. 3, pp. 1760-1776, 2017.

[8] Z. Zhou, H. Wang, X. Cai, L. Chen, E. Yude, and R. Cheng, "Damage evolution and failure behavior of post-mainshock damaged rocks under aftershock effects," Energies, vol. 12, no. 23, 2019.

[9] Y. Liu, F. Dai, L. Dong, N. Xu, and P. Feng, "Experimental investigation on the fatigue mechanical properties of intermittently jointed rock models under cyclic uniaxial compression with different loading parameters," Rock Mechanics and Rock Engineering, vol. 51, no. 1, pp. 47-68, 2018.

[10] M. C. Larsen and A. Simon, "A rainfall intensity-duration threshold for landslides in a humid-tropical environment, Puerto Rico," Physical Geography, vol. 75, no. 1-2, pp. 13-23, 2017.

[11] R. M. Iverson, "Landslide triggering by rain infiltration," Water Resources Research, vol. 36, no. 7, pp. 1897-1910, 2000.

[12] D. K. Keefer, "Investigating landslides caused by earthquakes a historical review," Surveys in Geophysics, vol. 23, no. 6, pp. 473-510, 2002.

[13] M. D. Zoback and J. D. Byerlee, "Permeability and effective stress: geologic notes," AAPG Bulletin, vol. 59, pp. 154-158, 1976.

[14] K. Iwai, "Fundamental studies of fluid flow through a single fracture," in International Journal of Rock Mechanics and Mining Sciences, $\mathrm{PhD}$ Thesis, University of California, Berkeley, 1976.

[15] Y. W. Tsang and P. A. Witherspoon, "Hydromechanical behavior of a deformable rock fracture subject to normal stress," Journal of Geophysical Research, vol. 86, no. B10, pp. 9287-9298, 1981.

[16] K. G. Raven and J. E. Gale, "Water flow in a natural rock fracture as a function of stress and sample size," International Journal of Rock Mechanics and Mining Sciences \& Geomechanics Abstracts, vol. 22, no. 4, pp. 251-261, 1985.

[17] W. B. Durham and B. P. Bonner, "Self-propping and fluid flow in slightly offset joints at high effective pressures," Journal of Geophysical Research, vol. 99, no. B5, pp. 9391-9399, 1994.
[18] H. S. Lee and T. F. Cho, "Hydraulic characteristics of rough fractures in linear flow under normal and shear load," Rock Mechanics and Rock Engineering, vol. 35, no. 4, pp. 299-318, 2002.

[19] B. Li, Y. Jiang, T. Koyama, L. Jing, and Y. Tanabashi, "Experimental study of the hydro-mechanical behavior of rock joints using a parallel-plate model containing contact areas and artificial fractures," International Journal of Rock Mechanics and Mining Sciences, vol. 45, no. 3, pp. 362-375, 2008.

[20] R. Olsson and N. Barton, "An improved model for hydromechanical coupling during shearing of rock joints," International Journal of Rock Mechanics and Mining Sciences, vol. 38, no. 3, pp. 317-329, 2001.

[21] Z. M. Shi, D. Y. Shen, Q. Z. Zhang, M. Peng, and Q. D. Li, "Experimental study on the coupled shear flow behavior of jointed rock samples," European Journal of Environmental and Civil Engineering, vol. 22, no. sup1, pp. s333-s350, 2018.

[22] C. Zhao, R. Zhang, Q. Zhang, Z. Shi, and S. Yu, "Shear-flow coupled behavior of artificial joints with sawtooth asperities," Processes, vol. 6, no. 9, p. 152, 2018.

[23] H. Zhang, Z. Wan, Z. Feng, and J. Wu, "Shear-induced permeability evolution of sandstone fractures," Geofluids, vol. 2018, 11 pages, 2018.

[24] W. Wu, J. S. Reece, Y. Gensterblum, and M. D. Zoback, "Permeability evolution of slowly slipping faults in shale reservoirs," Geophysical Research Letters, vol. 44, no. 22, article 2416481, pp. 11,368-11,375, 2017.

[25] Z. Zhou, X. Cai, D. Ma et al., "Water saturation effects on dynamic fracture behavior of sandstone," International Journal of Rock Mechanics and Mining Sciences, vol. 114, pp. 4661, 2019.

[26] Z. Zhou, X. Cai, X. Li, W. Cao, and X. Du, “Dynamic response and energy evolution of sandstone under coupled staticdynamic compression: insights from experimental study into deep rock engineering applications," Rock Mechanics and Rock Engineering, 2019.

[27] Z. Zhou, X. Cai, D. Ma, L. Chen, S. Wang, and L. Tan, "Dynamic tensile properties of sandstone subjected to wetting and drying cycles," Construction and Building Materials, vol. 182, pp. 215-232, 2018.

[28] Z. Zhou, R. Cheng, X. Cai, J. Jia, and W. Wang, "Comparison of presplit and smooth blasting methods for excavation of rock wells," Shock and Vibration, vol. 2019, Article ID 3743028, 12 pages, 2019.

[29] X. Z. Lyu, Z. Zhao, X. Wang, and W. Wang, "Study on the permeability of weakly cemented sandstones," Geofluids, vol. 2019, Article ID 8310128, 14 pages, 2019.

[30] Y. Wang, X. Zhou, and M. Kou, "An improved coupled thermo-mechanic bond-based peridynamic model for cracking behaviors in brittle solids subjected to thermal shocks," European Journal of Mechanics - A/Solids, vol. 73, pp. 282305, 2019.

[31] D. Ma, J. Wang, X. Cai et al., "Effects of height/diameter ratio on failure and damage properties of granite under coupled bending and splitting deformation," Engineering Fracture Mechanics, vol. 220, p. 106640, 2019.

[32] W. Dang, H. Konietzky, T. Frühwirt, and M. Herbst, "Cyclic frictional responses of planar joints under cyclic normal load conditions: laboratory tests and numerical simulations," Rock Mechanics and Rock Engineering, pp. 1-28, 2019. 
[33] S. Wang, X. Li, J. Yao et al., "Experimental investigation of rock breakage by a conical pick and its application to non-explosive mechanized mining in deep hard rock," International Journal of Rock Mechanics and Mining Sciences, vol. 122, p. 104063, 2019.

[34] M. Kou, X. Liu, S. Tang, and Y. Wang, "3-D X-ray computed tomography on failure characteristics of rock-like materials under coupled hydro-mechanical loading," Theoretical and Applied Fracture Mechanics, vol. 104, p. 102396, 2019.

[35] Z. Song, H. Konietzky, and T. Frühwirt, "Hysteresis energybased failure indicators for concrete and brittle rocks under the condition of fatigue loading," International Journal of Fatigue, vol. 114, pp. 298-310, 2018.

[36] W. Dang, H. Konietzky, L. Chang, and T. Frühwirt, "Velocityfrequency-amplitude-dependent frictional resistance of planar joints under dynamic normal load (DNL) conditions," Tunnelling and Underground Space Technology, vol. 79, pp. 27-34, 2018.

[37] S. F. Wang, L. Q. Huang, and X. B. Li, “Analysis of rockburst triggered by hard rock fragmentation using a conical pick under high uniaxial stress," Tunnelling and Underground Space Technology, vol. 96, p. 103195, 2020.

[38] K. Peng, J. Q. Zhou, Q. L. Zou, and F. Z. Yan, “Deformation characteristics of sandstones during cyclic loading and unloading with varying lower limits of stress under different confining pressures," International Journal of Fatigue, vol. 127, pp. 82-100, 2019.

[39] Z. Song, H. Konietzky, and M. Herbst, "Bonded-particle model-based simulation of artificial rock subjected to cyclic loading," Acta Geotechnica, vol. 14, no. 4, pp. 955-971, 2019.

[40] K. Peng, J. Zhou, Q. Zou, J. Zhang, and F. Wu, “Effects of stress lower limit during cyclic loading and unloading on deformation characteristics of sandstones," Construction and Building Materials, vol. 217, pp. 202-215, 2019.

[41] P. Kang, L. Zhaopeng, Z. Quanle, Z. Zhenyu, and Z. Jiaqi, "Static and dynamic mechanical properties of granite from various burial depths," Rock Mechanics and Rock Engineering, vol. 52, no. 10, pp. 3545-3566, 2019.

[42] K. Peng, Y. Wang, Q. Zou, Z. Liu, and J. Mou, "Effect of crack angles on energy characteristics of sandstones under a complex stress path," Engineering Fracture Mechanics, vol. 218, p. $106577,2019$.

[43] Z. Song, T. Frühwirt, and H. Konietzky, "Inhomogeneous mechanical behaviour of concrete subjected to monotonic and cyclic loading," International Journal of Fatigue, vol. 132, p. 105383, 2020.

[44] W. Dang, W. Wu, H. Konietzky, and J. Qian, "Effect of shearinduced aperture evolution on fluid flow in rock fractures," Computers and Geotechnics, vol. 114, p. 103152, 2019.

[45] D. Ma, H. Duan, X. Li, Z. Li, Z. Zhou, and T. Li, "Effects of seepage-induced erosion on nonlinear hydraulic properties of broken red sandstones," Tunnelling and Underground Space Technology, vol. 91, p. 102993, 2019.

[46] X. F. Li, H. B. Li, and G. K. Zhang, "Damage assessment and blast vibrations controlling considering rock properties of underwater blasting," International Journal of Rock Mechanics and Mining Sciences, vol. 121, p. 104045, 2019.

[47] M. Zhang, L. Dou, H. Konietzky, Z. Song, and S. Huang, "Cyclic fatigue characteristics of strong burst-prone coal: experimental insights from energy dissipation, hysteresis and micro-seismicity," International Journal of Fatigue, vol. 133, p. 105429, 2020.

[48] X. Cai, Z. Zhou, K. Liu, X. du, and H. Zang, "Water-weakening effects on the mechanical behavior of different rock types: phenomena and mechanisms," Applied Sciences, vol. 9, no. 20, p. 4450, 2019.

[49] W. F. Brace, J. B. Walsh, and W. T. Frangos, "Permeability of granite under high pressure," Journal of Geophysical Research, vol. 73, no. 6, pp. 2225-2236, 1968.

[50] Y. Zhao, L. Zhang, W. Wang, J. Tang, H. Lin, and W. Wan, "Transient pulse test and morphological analysis of single rock fractures," International Journal of Rock Mechanics and Mining Sciences, vol. 91, pp. 139-154, 2017.

[51] H. Jang, J. Lee, and W. Lee, "Experimental apparatus and method to investigate permeability and porosity of shale matrix from Haenam Basin in Korea," Environmental Earth Sciences, vol. 74, no. 4, pp. 3333-3343, 2015.

[52] D. Vogler, F. Amann, P. Bayer, and D. Elsworth, "Permeability evolution in natural fractures subject to cyclic loading and gouge formation," Rock Mechanics and Rock Engineering, vol. 49, no. 9, pp. 3463-3479, 2016.

[53] E. H. Rutter and J. Mecklenburgh, "Influence of normal and shear stress on the hydraulic transmissivity of thin cracks in a tight quartz sandstone, a granite, and a shale," Journal of Geophysical Research-Solid Earth, vol. 123, no. 2, pp. 1262 1285, 2018.

[54] W. Liu and M. Manga, "Changes in permeability caused by dynamic stresses in fractured sandstone," Geophysical Research Letters, vol. 36, no. 20, pp. 2-5, 2009.

[55] T. Candela, E. E. Brodsky, C. Marone, and D. Elsworth, "Laboratory evidence for particle mobilization as a mechanism for permeability enhancement via dynamic stressing," Earth and Planetary Science Letters, vol. 392, pp. 279-291, 2014.

[56] J. E. Elkhoury, E. E. Brodsky, and D. C. Agnew, "Seismic waves increase permeability," Nature, vol. 441, no. 7097, pp. 11351138, 2006.

[57] K. B. Min, J. Rutqvist, C. F. Tsang, and L. Jing, "Stress-dependent permeability of fractured rock masses: a numerical study," International Journal of Rock Mechanics and Mining Sciences, vol. 41, no. 7, pp. 1191-1210, 2004. 